\title{
Case fatality rates of COVID-19 across the globe: are the current draconian measures justified?
}

\author{
Jayadevan Sreedharan ${ }^{1} \cdot$ Satish Chandrasekhar Nair ${ }^{2}$. Jayakumary Muttappallymyalil ${ }^{1}$. Aji Gopakumar ${ }^{3}$. \\ Neena Thomas Eapen ${ }^{4} \cdot$ Karthyayani Priya Satish ${ }^{5} \cdot$ Venkatramana Manda $^{1}$
}

Received: 29 April 2020 / Accepted: 16 February 2021 / Published online: 24 March 2021

(C) The Author(s), under exclusive licence to Springer-Verlag GmbH Germany, part of Springer Nature 2021

\begin{abstract}
Aim The current study assessed the case fatality rate (CFR) across different income level countries of the world, and the virulence pattern of COVID-19, against the backdrop of panic and uncertainty faced by many governments, who are trying to impose draconian containment measures to control the outbreak. Subjects and Methods: Data on confirmed cases and number of deaths due to coronavirus infection were retrieved from the WHO as on 30 March 2020, and examined for the various income level countries, per the World Bank criteria. The CFR was calculated country-wise and estimated for the various groups such as low, lower-middle, upper-middle, and high-income, and the data was analyzed.

Results The overall CFR for the high income countries was 5.0\%, compared with a CFR of $2.8 \%$ for low-income countries. The upper-middle-income countries showed a CFR of $4.3 \%$, while the lower-middle-income countries stood at $3.7 \%$. The results from our study predict that the maximum CFR in high-income countries will be contained at approximately 5\% (95\% CI). The CFR for the low, lower-middle, and upper-middle-income countries will range between 2.8 and $4.3 \%$ (95\% CI).

Conclusion COVID-19, irrespective of its transmissibility, produces a lower CFR compared with that of SARS-Cov and MERSCov, although COVID-19 has infected eight times more countries than MERS-Cov and SARS-Cov, and caused a higher number of deaths. The nation-wide lockdown measures to prevent the spread of the virus may be reconsidered, given the hardships for the population and their impact on the economic system.
\end{abstract}

Keywords Novel corona virus · Control measures $\cdot$ Level of income $\cdot$ Global picture $\cdot$ Quarantine

\section{Introduction}

In recent years, several coronaviruses (Cov) such as the 229E (alpha Cov), NL63 (alpha Cov), HKU1 (beta Cov), OC43 (beta Cov), MERS-Cov (the beta Cov that causes Middle East Respiratory Syndrome, or MERS) and SARS-Cov (the

Jayadevan Sreedharan

drjayadevans@gmail.com

1 College of Medicine, Gulf Medical University, P O Box 4184, Ajman, UAE

2 Tawam Hospital Johns Hopkins Medicine Affiliate and College of Medicine, UAE University, Al Ain, UAE

3 Institutional Research Unit, Gulf Medical University, P O Box 4184, Ajman, UAE

4 College of Medicine, University of Kentucky, Lexington, USA

5 Kasturba Medical College, Mangalore, India beta Cov that causes severe acute respiratory syndrome or SARS) have inflicted disease and deaths globally ( $\mathrm{Li}$ et al. 2020; Nassar et al. 2018; Wang et al. 2020; Zhong et al. 2003). The coronaviruses are capable of transmission from animal to animal, animal to human, and human to human. SARS-Cov, transmitted from bats to civet cats to humans, caused infection with an outcome of 8000 deaths in 26 countries, followed by MERS-Cov, transmitted from dromedary camels to humans, which caused severe symptoms and deaths in 27 countries (WHO 2020a). The ribonucleic acid, or RNA virus called the novel coronavirus (SARS-CoV-2), named for the crown-like spikes on its surface, has rapidly spread across 205 countries since the first reported outbreak in December 2019, from Wuhan, China, and the disease it causes is called COVID-19. COVID-19 infection, declared a global pandemic by the WHO on March 11, 2020, causes flu-like symptoms in humans, followed by severe respiratory failure in high risk cases, similar to the SARS-Cov virus (Chan et al. 2020; Zhou et al. 2020). The case fatality rate (CFR) for COVID- 
19 was high in the initial stages of the pandemic. This can be attributed to the fact that the majority of the cases admitted to hospital were at the severe stage and required critical care support. Additionally, an increase in fatality could be due to the role of associated co-morbid conditions compared with other corona virus outbreaks. The almost 2 million patients infected, $30 \%$ of them in severe condition, and infectionrelated deaths greater than 150,000 have stressed the world both in terms of inadequate healthcare resources and economic crises. The high transmissibility of COVID-19 and its grave impact on healthcare systems have caused concern, even for scientifically and economically advanced countries such as the United States, Canada, Germany, China, and France, as well as the less advanced countries. It is therefore important to understand the transmissibility pattern and the impact of COVID-19. To address this question, the current study assesses the CFR across different income level countries of the world. This, in turn, will be useful to evaluate viable solutions to confront the outbreak.

The current study gives overall CFR, which has been compared among high-income countries and low-income countries. This is the first report that examines the virulence pattern for the various income level countries of the world, in an attempt to predict worst-case scenarios, and to assist governments in decisions regarding adoption of draconian measures of containment such as a nation-wide lockdown. This, in turn, will prevent population hardships and economic crises. Reliable sources such as the WHO daily status reports, World Bank, Worldometer, and World Population Reviews have provided information for general population awareness since the outbreak (World Bank 2020). Peer-reviewed full-length scientific papers from Pub-Med, Medline, the Institute of Scientific Information, and the Cochrane Database of Systematic Reviews have documented the clinical course for COVID-19. Websites of various health ministries and allied governments share notifications for the well-being of the population. Although updated information is presented by these various sources, COVID-19 infectivity and virulence patterns related to case fatalities and based on income levels of countries is lacking. This study predicts the maximum CFR for many of the hotspot countries infected with COVID-19 and causing deaths. The CFR for COVID-19 is low compared with other recent coronaviruses such as SARS-Cov and MERS-Cov, although it has infected eightfold more countries that the other two coronaviruses combined due to its virulence. This study was conducted on low, lower-middle, upper-middle, and high-income level countries. The results of our study will benefit epidemiologists, health professionals, policymakers, economists, and governments to balance solutions, evaluate the adoption of draconian containment measures, and enable prevention of an economic crisis.

\section{Methods}

Country-wise numbers of confirmed cases of coronavirus infection and deaths were retrieved from the World Health Organization (WHO) COVID-19 as on March 30, 2020 (WHO 2020b). The number of cases and deaths were accessed from the site and included a total of 202 countries along with their territories. In addition to electronic data sources, databases such as Pub-Med, Medline, the Institute of Scientific Information, and the Cochrane Database of Systematic Reviews published scientific papers and ministries of health reports for Asia, the Middle East, and Africa, and government notifications from the various countries affected were also employed for the study. Appropriate keywords used to search the literature included, but were not limited to, coronavirus infection, Middle East Respiratory Syndrome, Severe Acute Respiratory Syndrome, virulence, fatality, cases, death, RNA viruses, COVID-19, $2019 \mathrm{nCOV}$, and viral genes (WHO $2020 \mathrm{c}$, d). Only full-length publications were included, and those in languages other than English were excluded for the study. The various countries were categorized based on income into four groups, namely low, lower-middle, upper-middle, and high-income as per the World Bank criteria (World Bank 2020). The CFR was calculated country-wise and plotted for the various groups. The retrieved data were analyzed in SPSS version 26. The results were communicated in frequency and percentages and depicted in tables and graphs.

\section{Results}

The CFR due to novel coronavirus infection is given in the following tables. Analysis included 190 countries. Among the total 24 low-income countries, 17 (71\%) reported no mortality from COVID-19, in spite of reported cases (Fig. 1). The CFR and confidence interval (CI) of CFR for low-income countries are given in Table 1. Some reported very few cases. The overall CFR in the low-income countries amounted to $2.8 \%$, although some countries showed a high CFR, accounted for by the very low number of cases. Based on our analysis, with 95\% CI and no statistical significance, it can be safely assumed that the seven countries that did not report any fatalities will also not experience any if the current trend continues. However, in some low-income countries where the CFR was high and significant, for example, the Democratic Republic of Congo (CFR 16) and Afghanistan (CFR 7), the trend predicts that the CFR in such low-income countries may reach closer to $4 \%$ with $95 \%$ CI (Table 1).

Similar to the low-income countries, 20 (51.3\%) lowermiddle-income countries from a total of 39 did not report any fatalities, although COVID-19 positive cases had been reported (Fig. 1). The Philippines, Morocco, Egypt, and Bangladesh show high CFR compared to other countries in 
Table 1 Case fatality rate and its confidence interval in lowincome and lower-middle-income countries reported with COVID19 mortality

\begin{tabular}{|c|c|c|c|c|c|c|c|}
\hline \multirow[t]{2}{*}{ Economic level } & \multirow[t]{2}{*}{ No. } & \multirow[t]{2}{*}{ Country } & \multirow[t]{2}{*}{ No. of cases } & \multirow[t]{2}{*}{ No. of deaths } & \multirow[t]{2}{*}{ CFR* $(\%)$} & \multicolumn{2}{|c|}{ Confidence interval } \\
\hline & & & & & & Lower & Upper \\
\hline \multirow[t]{8}{*}{ Low } & 1 & Burkina Faso & 222 & 3 & 1.35 & -0.17 & 2.87 \\
\hline & 2 & Afghanistan & 114 & 4 & 3.51 & 0.13 & 6.89 \\
\hline & 3 & Togo & 28 & 1 & 3.57 & -3.30 & 10.44 \\
\hline & 4 & DR Congo & 81 & 8 & 9.88 & 3.38 & 16.38 \\
\hline & 5 & Syria & 9 & 1 & 11.11 & -9.42 & 31.64 \\
\hline & 6 & Niger & 20 & 3 & 15.00 & -0.65 & 30.65 \\
\hline & 7 & Gambia & 3 & 1 & 33.33 & -20.01 & 86.67 \\
\hline & & Total & 745 & 21 & 2.80 & 1.62 & 3.98 \\
\hline \multirow[t]{20}{*}{ Lower-middle } & 1 & Moldova & 263 & 2 & 0.76 & -0.29 & 1.81 \\
\hline & 2 & Pakistan & 1625 & 18 & 1.11 & 0.60 & 1.62 \\
\hline & 3 & Uzbekistan & 145 & 2 & 1.38 & -0.52 & 3.28 \\
\hline & 4 & Nigeria & 65 & 1 & 1.54 & -1.45 & 4.53 \\
\hline & 5 & Cameroon & 113 & 2 & 1.77 & -0.66 & 4.20 \\
\hline & 6 & Honduras & 110 & 2 & 1.82 & -0.68 & 4.32 \\
\hline & 7 & Ukraine & 480 & 11 & 2.29 & 0.95 & 3.63 \\
\hline & 8 & Tunisia & 312 & 8 & 2.56 & 0.81 & 4.31 \\
\hline & 9 & India & 1071 & 29 & 2.71 & 1.74 & 3.68 \\
\hline & 10 & Ghana & 152 & 5 & 3.29 & 0.45 & 6.13 \\
\hline & 11 & Kenya & 25 & 1 & 4.00 & -3.68 & 11.68 \\
\hline & 12 & Philippines & 1418 & 71 & 5.01 & 3.87 & 6.15 \\
\hline & 13 & Morocco & 516 & 27 & 5.23 & 3.31 & 7.15 \\
\hline & 14 & Egypt & 609 & 40 & 6.57 & 4.60 & 8.54 \\
\hline & 15 & Indonesia & 1285 & 114 & 8.87 & 7.32 & 10.42 \\
\hline & 16 & Bangladesh & 49 & 5 & 10.2 & 1.73 & 18.67 \\
\hline & 17 & Zimbabwe & 5 & 1 & 20.00 & -15.06 & 55.06 \\
\hline & 18 & Nicaragua & 4 & 1 & 25.00 & -17.44 & 67.44 \\
\hline & 19 & Sudan & 6 & 2 & 33.33 & -4.39 & 71.05 \\
\hline & & Total & 9142 & 342 & 3.74 & 3.35 & 4.13 \\
\hline
\end{tabular}

*CFR Case fatality rate

the region. On the other hand, Zimbabwe, Nicaragua, and Sudan have reported CFR more than or equal to 20 , primarily because of the low number of cases. The overall CFR in the lower-middle-income region was $3.7 \%$. The $95 \%$ CI for the CFR in countries with high CFR are not statistically significant. The countries where non-significant CFR was observed were Moldova, Uzbekistan, Nigeria, Cameroon, Honduras, Kenya, Zimbabwe, Nicaragua, and Sudan. As per the current trend, Pakistan could experience a CFR of $2 \%$ and Ukraine, Tunisia, and India, a maximum of $4 \%$. Higher CFR up to a maximum of $6 \%$ can be predicted for Ghana and the Philippines, with Bangladesh experiencing the highest CFR in the group. Thus, the overall CFR for the lower-middleincome countries can be predicted to experience a maximum CFR of $4 \%$, based on Table 1.

The total number of cases reported are low in the uppermiddle-income countries, except for Georgia and Belarus. Twenty-five percent of the countries, from a total of 52, did not report any fatalities, although cases have been reported (Fig. 2). High CFR was observed in China, Albania, Paraguay, Algeria, Iran, Iraq, Gabon, and Guyana. Gabon and Guyana show high CFR because of the low number of cases. The overall CFR observed in the upper-middle-income countries was $4.3 \%$. Among the total of 40 upper-middleincome countries which reported mortality due to novel coronavirus, the estimate observed was not statistically significant in 16 countries, which included Gabon and Guyana with high CFR. The overall CFR is predicted to reach a maximum of $4.5 \%$ based on our analysis for the upper-middle-income countries, although Iraq, Algeria, and Iran may experience higher CFR than the group average (Table 2).

Twenty-seven countries (36\%) among the 75 high-income countries had no fatalities from COVID-19, in spite of positive cases (Fig. 2). The United Kingdom, France, the Netherlands, Spain, Italy, the Cayman Islands, and Curaçao showed high CFR compared to other countries in the region. Very few 
Fig. 1 Distribution of cases in low and lower-middle-income countries with no mortality

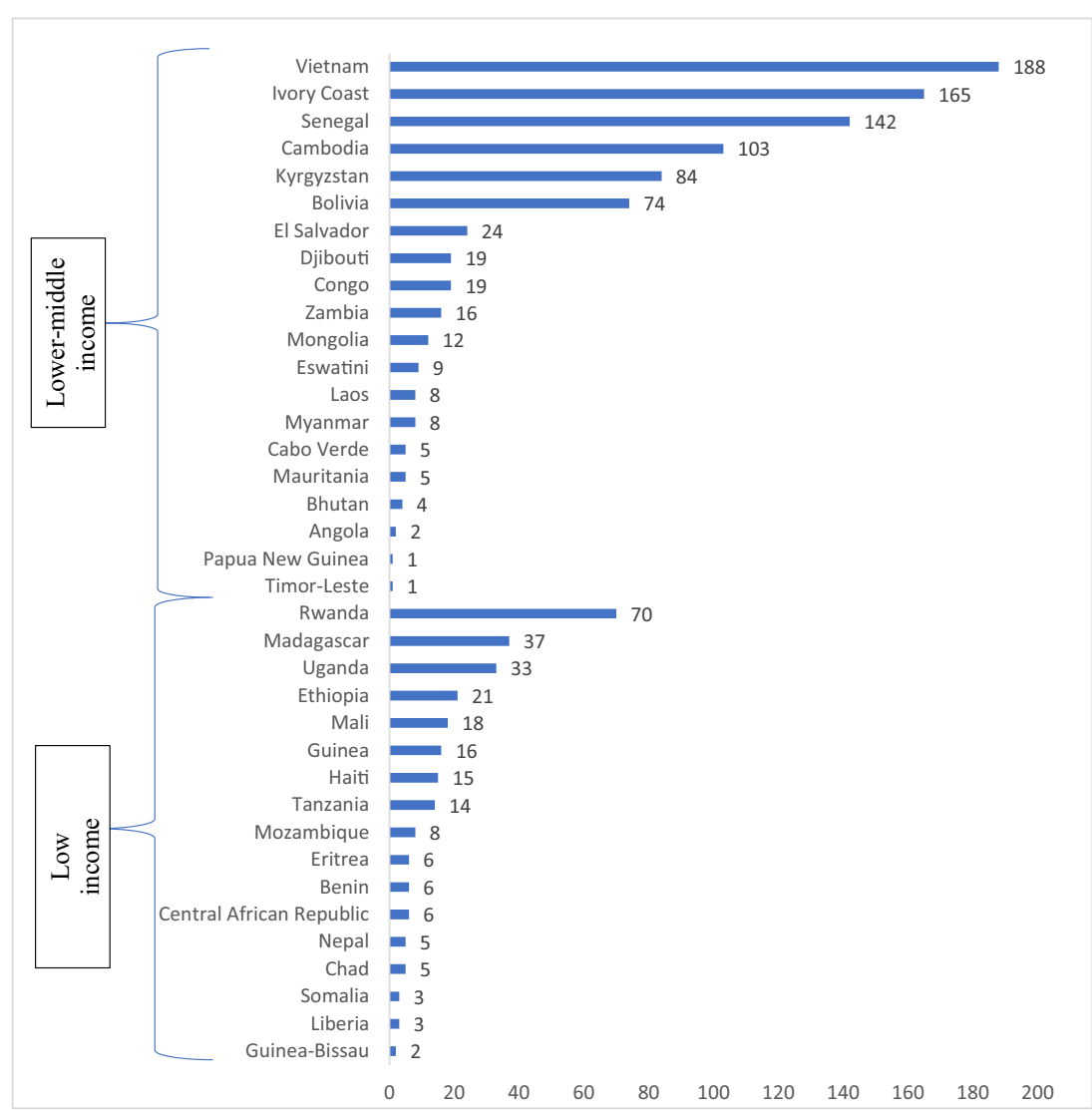

cases were reported from the Cayman Islands and Curaçao. As per the current trend, New Zealand, Iceland, Chile, Qatar, Israel, Singapore, Australia, Estonia, the United Arab Emirates, Norway, and Saudi Arabia can expect a maximum of $1 \%$ CFR. Puerto Rico may record a maximum CFR of $5 \%$. The other countries predicted to have higher CFR up to $11 \%$ are Trinidad and Tobago (6), the United Kingdom (6.5), France, the Netherlands (7.0), Spain (8.5), and Italy (11.2). The overall CFR for high-income countries is predicted to remain at approximately $5 \%$ based on our study (Table 3 ).

For comparison purposes, the CFR was grouped into categories of $0,<1,1-2,2-3,3-5,5-10$, and $>10$. It could be seen that the percentage of countries with no mortality decreases as the income of the country increases, except in the case of highincome countries. Overall, $41 \%$ of countries reported no mortality due to COVID-19. Approximately $25 \%$ of countries in the lower-income and lower-middle-income, and $20 \%$ of countries in the upper-middle-income and high-income groups reported a CFR of greater than $10 \%$.

\section{Discussion}

The world has responded to COVID-19 with fear, panic, and uncertainty, forcing governments to impose draconian containment measures such as travel bans, mandatory quarantine, and national sterilization and lockdown precautions lasting up to several weeks at a time ( $\mathrm{Wu}$ and McGoogan 2020). In order to assess the effectiveness of the containment measures, data were divided into four categories, namely low-income countries, lower-middle-income countries, upper-middle-income countries, and highincome countries. Our study assessed the CFR in 190 countries in all. The CFR was preferred over the infection fatality rate (IFR) because the CFR reflects the proportion of people who die from the disease having tested positive for it, whereas the IFR estimates the proportion of people who die after having the infection overall, meaning many positive cases may not have been included. Interestingly, the CFR pattern was strikingly different between the various groups of countries that we studied. The overall CFR for high-income countries was $5.0 \%$ (total cases 524,556, total deaths 26,153), compared with the CFR for low-income countries at $2.8 \%$ (total cases 745, total deaths 21) (Table 1). A distinct pattern was also evident when the CFR from the high-income countries was compared with the CFR in the upper-middleincome and lower-middle-income countries. The uppermiddle-income countries showed a CFR of $4.3 \%$ (total cases 153,689 , total deaths 6563 ), which is closer to the CFR of $5.0 \%$ observed in high-income countries (Table 3 ). The CFR for the lower-middle-income countries was $3.7 \%$ (total cases 9142, total deaths 342) (Table 1). 
Table 2 Case fatality rate and its confidence interval in uppermiddle-income countries with reported COVID-19 mortality

\begin{tabular}{|c|c|c|c|c|c|c|}
\hline \multirow[t]{2}{*}{ No. } & \multirow[t]{2}{*}{ Country } & \multirow[t]{2}{*}{ No. of cases } & \multirow[t]{2}{*}{ No. of deaths } & \multirow[t]{2}{*}{ CFR (\%) } & \multicolumn{2}{|l|}{ CI } \\
\hline & & & & & Lower & Upper \\
\hline 1 & South Africa & 1280 & 1 & 0.08 & -0.07 & 0.23 \\
\hline 2 & Kazakhstan & 294 & 1 & 0.34 & -0.33 & 1.01 \\
\hline 3 & Thailand & 1524 & 9 & 0.59 & 0.21 & 0.97 \\
\hline 4 & Armenia & 482 & 3 & 0.62 & -0.08 & 1.32 \\
\hline 5 & Russia & 1534 & 10 & 0.65 & 0.25 & 1.05 \\
\hline 6 & Costa Rica & 295 & 2 & 0.68 & -0.26 & 1.62 \\
\hline 7 & Sri Lanka & 120 & 1 & 0.83 & -0.79 & 2.45 \\
\hline 8 & Colombia & 608 & 6 & 0.99 & 0.20 & 1.78 \\
\hline 9 & Kosovo & 94 & 1 & 1.06 & -1.01 & 3.13 \\
\hline 10 & Jordan & 259 & 3 & 1.16 & -0.14 & 2.46 \\
\hline 11 & Montenegro & 85 & 1 & 1.18 & -1.12 & 3.48 \\
\hline 12 & Malaysia & 2470 & 34 & 1.38 & 0.92 & 1.84 \\
\hline 13 & Turkey & 9271 & 131 & 1.41 & 1.17 & 1.65 \\
\hline 14 & Peru & 671 & 11 & 1.64 & 0.68 & 2.60 \\
\hline 15 & Serbia & 741 & 13 & 1.75 & 0.81 & 2.69 \\
\hline 16 & Venezuela & 113 & 2 & 1.77 & -0.66 & 4.20 \\
\hline 17 & Bosnia and Herzegovina & 325 & 6 & 1.85 & 0.38 & 3.32 \\
\hline 18 & Mexico & 848 & 16 & 1.89 & 0.97 & 2.81 \\
\hline 19 & Mauritius & 102 & 2 & 1.96 & -0.73 & 4.65 \\
\hline 20 & Azerbaijan & 190 & 4 & 2.11 & 0.07 & 4.15 \\
\hline 21 & Romania & 1760 & 40 & 2.27 & 1.57 & 2.97 \\
\hline 22 & Lebanon & 438 & 10 & 2.28 & 0.88 & 3.68 \\
\hline 23 & Bulgaria & 346 & 8 & 2.31 & 0.73 & 3.89 \\
\hline 24 & North Macedonia & 259 & 6 & 2.32 & 0.49 & 4.15 \\
\hline 25 & Cuba & 119 & 3 & 2.52 & -0.30 & 5.34 \\
\hline 26 & Argentina & 745 & 19 & 2.55 & 1.42 & 3.68 \\
\hline 27 & Ecuador & 1835 & 48 & 2.62 & 1.89 & 3.35 \\
\hline 28 & Brazil & 3904 & 114 & 2.92 & 2.39 & 3.45 \\
\hline 29 & Guatemala & 34 & 1 & 2.94 & -2.74 & 8.62 \\
\hline 30 & Jamaica & 32 & 1 & 3.13 & -2.90 & 9.16 \\
\hline 31 & Dominican Republic & 581 & 20 & 3.44 & 1.96 & 4.92 \\
\hline 32 & China & 82,447 & 3310 & 4.01 & 3.88 & 4.14 \\
\hline 33 & Albania & 223 & 10 & 4.48 & 1.76 & 7.20 \\
\hline 34 & Paraguay & 59 & 3 & 5.08 & -0.52 & 10.68 \\
\hline 35 & Algeria & 454 & 29 & 6.39 & 4.14 & 8.64 \\
\hline 36 & Iran & 38,309 & 2640 & 6.89 & 6.64 & 7.14 \\
\hline 37 & Iraq & 547 & 42 & 7.68 & 5.45 & 9.91 \\
\hline 38 & Gabon & 7 & 1 & 14.29 & -11.64 & 40.22 \\
\hline \multirow[t]{2}{*}{39} & Guyana & 5 & 1 & 20 & -15.06 & 55.06 \\
\hline & Total & 153,689 & 6563 & 4.27 & 4.17 & 4.37 \\
\hline
\end{tabular}

No. Number of, CFR Case fatality rate, $C I$ Confidence interval
The overall estimated deaths during the Spanish flu pandemic from 1918 to 1920 reflected that the mortality rates in highincome countries were significantly lower than those in low, lower-middle, and upper-middle-income countries (Kilbourne 2006). Unlike the influenza and HIV epidemics, the brunt of the COVID-19 epidemic is carried by high-income countries
(Weiss 2003; Yuen et al. 2020) as evidenced by the CFR for these countries. In fact, the low and lower-middle-income countries, numbering approximately 63 , provide the COVID- 19 virus with a fertile environment to spread, arising from a plethora of factors, including poor socioeconomic conditions, compromised hygiene, high density of population, lack of access to 
Fig. 2 Distribution of cases in upper-middle and high-income countries with no mortality

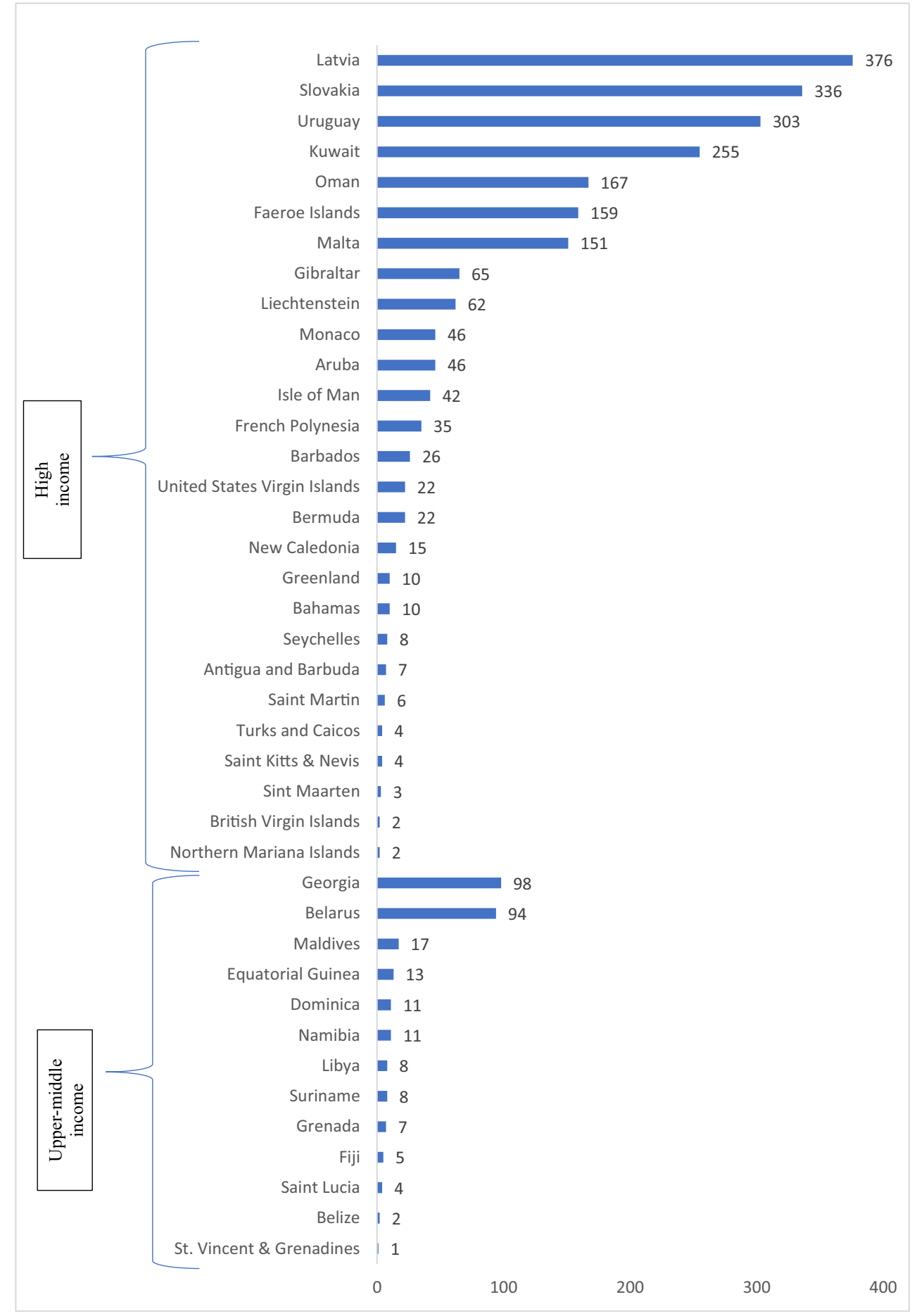

healthcare, economic disparity, cultural practices, and gender inequalities. The ease of implementing possible interventions in the high-income countries to control or mitigate the effects of a COVID-19 pandemic, such as antiviral agents, and nonpharmaceutical interventions such as quarantine, isolation, social distancing, and personal hygiene are a challenge for the low and lower-middle-income countries. Although the exact causes for the higher disease burden and the higher CFR in highincome countries are not clear, it may result from the high life expectancy and harboring of older populations with significant comorbidities (Beltrán-Sánchez et al. 2015). Several possibilities can be examined for the low CFR in the low and lowermiddle-income countries, including potential transmissibility of the virus, genetic profile of the population, and the survival rate of the virus in higher ambient temperatures (Brassey et al. 2020). More importantly, the underreporting of COVID-19 positive cases and lack of adequate testing measures may have contributed to the low number of positive cases being reported 
Table 3 Case fatality rate and its confidence interval in high-income countries with reported COVID-19 mortality

\begin{tabular}{|c|c|c|c|c|c|c|}
\hline \multirow[t]{2}{*}{ No. } & \multirow[t]{2}{*}{ Country } & \multirow[t]{2}{*}{ No. of cases } & \multirow[t]{2}{*}{ No. of deaths } & \multirow[t]{2}{*}{ CFR $(\%)$} & \multicolumn{2}{|l|}{ CI } \\
\hline & & & & & Lower & Upper \\
\hline 1 & New Zealand & 552 & 1 & 0.18 & 0.00 & 0.36 \\
\hline 2 & Iceland & 1020 & 2 & 0.20 & 0.06 & 0.34 \\
\hline 3 & Chile & 1909 & 6 & 0.31 & 0.18 & 0.44 \\
\hline 4 & Qatar & 634 & 2 & 0.32 & 0.10 & 0.54 \\
\hline 5 & Israel & 4247 & 15 & 0.35 & 0.26 & 0.44 \\
\hline 6 & Singapore & 844 & 3 & 0.36 & 0.15 & 0.57 \\
\hline 7 & Australia & 3966 & 16 & 0.40 & 0.30 & 0.50 \\
\hline 8 & Estonia & 679 & 3 & 0.44 & 0.19 & 0.69 \\
\hline 9 & United Arab Emirates & 570 & 3 & 0.53 & 0.23 & 0.83 \\
\hline 10 & Norway & 4102 & 22 & 0.54 & 0.43 & 0.65 \\
\hline 11 & Saudi Arabia & 1299 & 8 & 0.62 & 0.40 & 0.84 \\
\hline 12 & Bahrain & 515 & 4 & 0.78 & 0.39 & 1.17 \\
\hline 13 & Brunei & 126 & 1 & 0.79 & 0.00 & 1.58 \\
\hline 14 & Germany & 57,298 & 455 & 0.79 & 0.75 & 0.83 \\
\hline 15 & Croatia & 713 & 6 & 0.84 & 0.50 & 1.18 \\
\hline 16 & Finland & 1218 & 11 & 0.90 & 0.63 & 1.17 \\
\hline 17 & Austria & 8813 & 86 & 0.98 & 0.88 & 1.08 \\
\hline 18 & Luxembourg & 1950 & 21 & 1.08 & 0.85 & 1.31 \\
\hline 19 & Canada & 5655 & 61 & 1.08 & 0.94 & 1.22 \\
\hline 20 & Poland & 1862 & 22 & 1.18 & 0.93 & 1.43 \\
\hline 21 & Lithuania & 484 & 7 & 1.45 & 0.91 & 1.99 \\
\hline 22 & South Korea & 9661 & 158 & 1.64 & 1.51 & 1.77 \\
\hline 23 & United States & 122,653 & 2112 & 1.72 & 1.68 & 1.76 \\
\hline 24 & Ireland & 2615 & 46 & 1.76 & 1.50 & 2.02 \\
\hline 25 & Andorra & 341 & 6 & 1.76 & 1.05 & 2.47 \\
\hline 26 & Slovenia & 730 & 13 & 1.78 & 1.29 & 2.27 \\
\hline 27 & Guam & 56 & 1 & 1.79 & 0.02 & 3.56 \\
\hline 28 & Switzerland & 14,274 & 257 & 1.80 & 1.69 & 1.91 \\
\hline 29 & Panama & 901 & 17 & 1.89 & 1.44 & 2.34 \\
\hline 30 & Martinique & 105 & 2 & 1.90 & 0.57 & 3.23 \\
\hline 31 & Portugal & 5962 & 119 & 2. 00 & 1.82 & 2.18 \\
\hline 32 & Cyprus & 214 & 6 & 2.80 & 1.67 & 3.93 \\
\hline 33 & Japan & 1866 & 54 & 2.89 & 2.50 & 3.28 \\
\hline 34 & Sweden & 3700 & 110 & 2.97 & 2.69 & 3.25 \\
\hline 35 & Denmark & 2395 & 72 & 3.01 & 2.66 & 3.36 \\
\hline 36 & Puerto Rico & 64 & 2 & 3.13 & 0.95 & 5.31 \\
\hline 37 & Greece & 1156 & 38 & 3.29 & 2.77 & 3.81 \\
\hline 38 & Hungary & 447 & 15 & 3.36 & 2.51 & 4.21 \\
\hline 39 & Trinidad and Tobago & 76 & 3 & 3.95 & 1.72 & 6.18 \\
\hline 40 & Belgium & 10,836 & 431 & 3.98 & 3.79 & 4.17 \\
\hline 41 & United Kingdom & 19,526 & 1228 & 6.29 & 6.12 & 6.46 \\
\hline 42 & France & 39,642 & 2602 & 6.56 & 6.44 & 6.68 \\
\hline 43 & Netherlands & 10,866 & 771 & 7.10 & 6.85 & 7.35 \\
\hline 44 & Spain & 78,797 & 6528 & 8.28 & 8.18 & 8.38 \\
\hline 45 & San Marino & 229 & 24 & 10.48 & 8.46 & 12.50 \\
\hline 46 & Italy & 97,689 & 10,781 & 11.04 & 10.94 & 11.14 \\
\hline 47 & Cayman Islands & 8 & 1 & 12.50 & 0.81 & 24.19 \\
\hline \multirow[t]{2}{*}{48} & Curaçao & 7 & 1 & 14.29 & 1.06 & 27.52 \\
\hline & Total & 525,456 & 26,153 & 4.97 & 4.94 & 5.00 \\
\hline
\end{tabular}

No. Number of cases or deaths, $C F R$ Case fatality rate, $C I$ Confidence interval

from the low and lower-middle-income countries. The lag time for the virus to spread from China, although a significant variable, may have had some impact in the analysis of the CFR between the high-income countries and other groups. It is possible that the governments in the low and middle-income countries have had more time to restructure public health and clinical infrastructure to deal with this widespread health crisis.
Around the globe, governments, especially in the lowermiddle-income countries, have imposed mandatory quarantines, isolation measures, social distancing, personal hygiene, and national lockdown measures to control exposure, especially for vulnerable populations such as the elderly, people with comorbidities, pregnant woman, and children (Yuen et al. 2020). Although quarantine, isolation, social distancing, and personal 
hygiene were quiet easily adopted by most people, measures such as national lockdowns for weeks have generated a public outcry (Pulla 2020). The CFR ranged between $2.8 \%$ and $5.0 \%$ for the low to high-income countries in our study; hence, the rationale for national lockdowns cannot be justified based on our CFR data. The fatality rate for COVID-19 is low, compared with the fatality rate for other recent coronaviruses (MERS-Cov $858 / 2494=34 \%$, SARS $906 / 8098=11 \%$ ) and other viruses $($ Nipah 398/513 $=77 \%$ and Ebola 13,562/33,577=41\%) (Guo et al. 2020). In the light of our study, a nation-wide lockdown as implemented in several countries may not be the best option to control the outbreak. China, Italy, and Spain, all countries that have enforced nation-wide lockdown, are on the brink of economic crisis. Businesses rack up losses due to closures, and layoffs follow as revenue slumps. Consumption that significantly contributes to the gross domestic product of a country becomes affected in turn and uncertainties hold back household purchases. Investors refrain from investing in a volatile market. Disruptions in the global supply chain obstruct the manufacturing industry, exacerbated by poor consumption. The arts, and the entertainment, recreation, transportation, travel, and restaurant industries suffer closure resulting from lockdown and quarantines. Investments in real estate, home buying, and educational programs are delayed by the precautionary measures and because investors are unable to fathom the "real value" (Adam 2020).

Protective measures such as mandatory masking, checking for symptoms and objective findings of disease such as fever in travelers, aggressive quarantining of travelers, selective quarantining for vulnerable populations to prevent exposure, bans on non-essential travel, procurement and adherence to personal protective gear for health workers, social distancing, personal hygiene, and encouragement of non-touch greetings may be more prudent options.

Our study has several limitations. First, the data for the study were obtained from public domains, and second, the higher CFR $(>6.0 \%)$ reported for some countries irrespective of the income level indicated skewness of the data related to the extremely low number of cases and deaths reported (Tables 1, 2, and 3). The reliability of the public domain information from the WHO partially overcomes some of these limitations. The strength of the study is that this is the first report that addresses the virulence of COVID-19 and the effectiveness of national lockdowns, based on global CFR data. The results of our study will be useful for trying to implement interventions in cases of pandemics such as COVID-19, and others in the future, without being detrimental to economic pursuits.

\section{Conclusion}

Fear, panic, and uncertainty forced many governments to impose draconian containment measures to control the spread of COVID-19 infection. The results from our study predict that the maximum CFR in high-income countries will be contained at approximately 5\%. The CFR for the low, lower-middle, and upper-middle-income countries will range between $2.8 \%$ and $4.3 \%$. COVID-19, irrespective of its infectivity and virulence, produces a lower CFR compared with that of SARS-Cov and MERS-Cov, although COVID-19 has infected eight times more countries than MERS-Cov and SARS-Cov and caused a higher number of deaths. The nation-wide lockdown measures adopted to prevent the spread of the virus may have been prevented had the CFR been taken into account, and social engagement reforms and mandatory quarantine for travelers and vulnerable populations adopted instead. These measures would have minimized hardship for the population and prevented economic turmoil.

Acknowledgments The authors acknowledge support from the Gulf Medical University, Ajman and Tawam Hospital in the UAE, University of Kentucky in the USA, and Kasturba Medical College, Mangalore, India for their assistance in conducting this study.

Author contribution JDA conceived the study, collected, analyzed, and interpreted data, and prepared the manuscript, SCN was involved in the interpretation of results, discussions, writing the manuscript, and editing of the manuscript. JKM retrieved the data, interpreted results, and wrote the manuscript. AGK conducted literature search, retrieved data, and analyzed data. NTE was involved in writing the manuscript. KPS was involved in literature search and data collection. MVR contributed to writing and editing of the manuscript. All the authors have reviewed and approved the manuscript and provided valuable comments.

Funding The study is not funded by any funding agency.

Data availability Data was retrieved from the public websites such as the WHO, World Bank, and other sources such as PubMed and Medline. Its public domain information have been cited in the manuscript. Data from the study will be archived at the institutional data archive of the Gulf Medical University and released to anyone interested upon appropriate request.

\section{Declarations}

Ethics approval This study did not require ethics approval sine no patients or patient's materials was involved in the study.

Conflict of interest The authors declare that they have no conflict of interest.

\section{References}

Adam D (2020) Special Report: The simulations driving the worlds response to COVID-19. Available from https:/www.nature.com/ articles/d41586-020-01003-6 (accessed April 4, 2020)

Beltrán-Sánchez H, Soneji S, Crimmins EM (2015) Past, present, and future of healthy life expectancy. Cold Spring Harb Perspect Med 5(11):a025957. https://doi.org/10.1101/cshperspect.a025957

Brassey J, Heneghan C, Mahtani KR, et al (2020) Do weather conditions influence the transmission of COVID-19? https://www.cebm.net/ 
Covid19/do-weather-conditions-influence-the-transmission-of-thecoronavirus-sars-cov-2. Accessed 6 April 2020

Chan JF, Kok KH, Zhu Z et al (2020) Genomic characterization of the 2019 novel human-pathogenic coronavirus isolated from patients with acute respiratory disease in Wuhan, Hubei, China. Emerg Microb Infect 9(1):221-236

COVID-19 (2020) MERS \& SARS. https://www.niaid.nih.gov/diseasesconditions/Covid19 (accessed April 4, 2020)

Guo Y, Cao Q, Hong Z et al (2020) The origin, transmission and clinical therapies on coronavirus disease 2019 (COVID-19) outbreak - an update on the status, Military Med Res 7(11). https://doi.org/10. 1186/s40779-020-00240-0

Kilbourne ED (2006) Influenza pandemics of the 20th century. Emerg Infect Dis 12:9-14

Li Q, guan X, Wu P et al (2020) Early transmission dynamics in Wuhan, China, of novel coronavirus-infected pneumonia. N Engl J Med 382:1199-1207

Nassar MS, Ma B, Meo SA et al (2018) Global seasonal occurrence of middle east respiratory syndrome coronavirus (MERS-CoV) infection. Eur Rev Med Pharmacol Sci 22:3913-3918

Pulla P (2020) COVID-19: India imposes lockdown for 21 days and cases rise. BMJ 368:m1251. https://doi.org/10.1136/bmj.m1251

Wang C, Horby PW, Hayden FG et al (2020) A novel coronavirus outbreak of global health concern. Lancet 335(10223):470-473

Weiss RA (2003) HIV and AIDS in relation to other pandemics. Among the viruses plaguing humans, HIV is a recent acquisition. Its outstanding success as an infection poses immense scientific challenges to human health and raises the question "What comes nest?". EMBO Reports 4 Spec No(Suppl 1):S10-S14. https://doi.org/10.1038/sj. embor.embor857

World Bank (2020) New country classifications by income level: 20192020. https://blogs.worldbank.org/opendata/new-countryclassifications-income-level-2019-2020. Accessed 1 Apr 2020
World Health Organization (WHO) (2020a) Middle East Respiratory Syndrome coronavirus (MERS-CoV). https://www.who.int/ emergencies/mers-cov/en/. Accessed 3 Apr 2020

World Health Organization (WHO) (2020b) Situation Report - 70. Coronavirus disease 2019 (COVID-19). https://www.who.int/ emergencies/diseases/novelcoronavirus-2019/situation-reports/. Accessed 3 Apr 2020

World Health Organization (WHO) (2020c) Summary table of SARS cases by country, 1 November 2002-7 August 2003. https://www. who.int/csr/sars/country/2003_08_15/en/. Accessed 3 Apr 2020

World Health Organization (WHO) (2020d) Coronavirus. Available at: https://www.who.int/health-topics/coronavirus. Accessed 2 Apr 2020

Wu Z, McGoogan JM (2020) Characteristics of and important lessons from the coronavirus disease 2019 (COVID-19) outbreak in China: summary of a report of 72314 cases from the Chinese Center for Disease Control and Prevention. JAMA 323(13):1239-1242. https://doi.org/10.1001/jama.2020.2648

Yuen KS, Ye ZW, Fung SY et al (2020) SARS-CoV-2 and COVID-19: the most important research questions. Cell Biosci 10:40

Zhong NS, Zheng BJ, Li YM et al (2003) Epidemiology and cause of severe acute respiratory syndrome (SARS) in Guangdong, People's Republic of China in February 2003. Lancet 362:1353-1358

Zhou P, Yang XL, Wang XG et al (2020) Discovery of a novel coronavirus associated with the recent pneumonia outbreak in humans and its potential bat origin. Nature 579(7798):270-273

Publisher's note Springer Nature remains neutral with regard to jurisdictional claims in published maps and institutional affiliations. 